\title{
The Practice of English Listening Comprehension Teaching
}

\author{
Jiang Qian \\ School of Foreign Languages, Yunnan Normal University, Kunming, Yunnan, P. R. China \\ 1271530736@qq.com
}

Keywords: Listening comprehension, Language teaching, Scaffolding strategy, Authentic materials.

\begin{abstract}
Listening comprehension is an important component of language learning and has gained more and more awareness in China's language teaching. The emphasis on listening comprehension at all levels of English language teaching and learning has recently been strengthened greatly in Chinese universities. However, most EFL learners in Chinese university find it difficult for them to improve from lower or intermediate level of listening ability to a higher level. This paper explains and demonstrates how to help EFL learners achieve advanced level of listening ability by adopting scaffolding strategy with authentic materials in listening comprehension teaching and learning.
\end{abstract}

\section{Introduction}

Among the four language skills, listening in almost any setting is the most frequently used skill. Listening comprehension has become the key stone of many theories of second language acquisition and instructions which focus on the beginning levels of second language proficiency. Since listening comprehension plays a key role in facilitating language learning, listening teaching constitutes a certain part of the English curricula in schools and colleges, and listening instruction should be regarded as a very important part of any EFL program.

However, most EFL learners in Chinese universities usually score lower in listening comprehension tests than in tests of grammar, vocabulary, reading and writing. Deficient listening skills are the main cause of failure in tests. The student's listening ability usually stop at word-level, that is, they can catch every word and syllables, but they do not have enough spare time and attentional capacity to construct global meaning. Linguistically more difficult listening materials are very difficult for them to comprehend, so, a conventional listening comprehension lesson usually focuses on the elementary or intermediate level. However, by using authentic listening materials and adopting the scaffolding theory, jumping to a high level of listening ability is possible.

\section{Literature Review}

\subsection{Authentic Materials used in English listening comprehension teaching}

Listening comprehension is an active process which involves identifying the sounds, understanding the vocabulary and grammatical structures, interpretation of the stress and intonations as well as the larger socio-cultural context of the utterance [1]. According to Krashen, listening may form the basis of all further learning.[2] In the universities of Yunnan Province in China, there are not many opportunities for EFL learners to be exposed to real native-speaker discourse. In most situations, the only "foreign" voice the students heard in universities is that of the teacher, who frequently was not a native speaker himself. Most of the listening materials are written for nonnative speakers and lack of naturalness and authenticity.

However, more and more teachers are recognizing the advantage of topical, up-to-date material for classroom use, which is much more appealing to students than older, out-of-date material. One advantage for authentic materials is that they can give examples of the hesitations, false starts, filled and empty pauses which are characters of natural speech. Authentic recordings may provide the students with some valuable access to native discourse when the teacher's pronunciation is noticeably foreign [3]. It is therefore helpful to introduce among the classroom teaching in universities pieces of 
authentic listening along with scripted texts, to help learners to become familiar with the cadences of the target language, and to help them achieve a high level of listening ability.

One inexhaustible source of authentic language adopted in university for English major students is the international radio broadcast, The Voice of America (VOA) broadcasting. With its varied and interesting program, VOA has become one of the main resources for Chinese learners of English. The acquisition of a second language means not only to acquire the language itself, but also the culture of the language, therefore, a listening-comprehension course became essential not only for improvement in an elementary level, but also for developing listening skills and broadening the student's language knowledge and culture of the language at a higher level. VOA English programs can be used to fulfil this requirements.

The programs contain two parts which are appropriate to listening comprehension course. One is VOA "Special English" programs which are scripted with a controlled vocabulary and short, direct sentences, and are presented at a slower than normal speed, providing opportunities for lower-level learners to use their existing language skills. This enable them to focus their attention on comprehending the content. The other is the VOA " standard English" programs. With their diverse linguistic features, the standard English programs can serve as "real life" situation, which prove very useful in building ESL learners' competence in their communication skills. Both of the two parts of the program cover a wide range of subjects in American culture from world news to history and entertainment, all of which are interesting and motivating, thus it can be adopted to various levels in classroom teaching.

It should be indicated that VOA broadcasting Program is fresh every day. Because of its variety of the contents and different authentic topics, teachers can develop different listening strategies to arouse the learners interests. The learner can be benefit from exposure to a continuous flow of English everyday from these sources. This can be an invaluable source for teaching listening comprehension on situations where there is not sufficient access to native-speaker discourse.

\subsection{Scaffolding strategy used in English listening comprehension teaching}

While authentic materials are often stressed in the listening teaching, the scaffolding theory is seldom stressed when it goes with authentic materials. Scaffolding is explained in Longman Dictionary of Language Teaching \& Applied Linguistics as " the building of a target language structure over several TURNs in an interaction." [4].

Vygostsky proposes that there are in fact two developmental levels of students development. The first is " actual development", which is what a child can do alone at this point in time. The second, "potential development" is what a child can achieve if given the benefit of support during the task. Vygostsky suggests that there is always a difference between these two forms of development and that this gap, called " Zone of Proximal Development". [5] ZPD is critical for language learning and instruction.

The term scaffold is used to characterize adult assistance to children's language development. The assistance can be employed to help students to achieve at their potential development level. Scaffolding is a process the teacher helps students by doing what they cannot do at first, and allowing students to slowly take over parts of the text construction process as they are able to do so. The teacher controls the focus of attention, demonstrates and segments the task and so on. Scaffolding is thought to be one way in which learners acquire new linguistic structures.Listening comprehension ability also can be stretched to achieve the potential development level by providing scaffolding help. Vygotsky argues that good learning is in advance of development [5]. Teacher can provide students with scaffolding assistance and authentic listening materials to help them achieve higher level of listening competence. In other words, teacher can provide students with suitable listening materials, background information and linguistic knowledge, enabling skills, and useful exercises to help them develop effective listening strategies [6]. 


\section{Application of scaffolding strategy and authentic materials in listening comprehension teaching}

According to Wood, Bruner, and Ross, scaffolding is characterized by the following features:[7]

1.Getting learners interested in a task.

VOA News broadcasting is an authentic material to improve listening comprehension. Students can get access to real native speaking discourse and be motivated by the related background culture and the other information of the world. In each class, teacher can provide students with different up-to-date news from VOA programs. Students interests can be aroused by this authentic listening materials.

\section{Simplifying the task.}

The aim of this approach is to help students cover the gap between the comprehension of Special English and of Standard English by providing scaffolding help to stretch their listening ability, thus help them achieve their potential development level. The materials should be carefully organized. It should progress step by step from semi-authenticity that displays most of the linguistic features of natural speech to total authenticity, because to understand natural speech in real life is the final aim [6]. The main focus should be on the comprehension of Standard English program. The teacher record from the Standard English news the same topic he records from the Special English. Both of the two pieces of news are about the same topic. Teacher can play the Special English first to students, which is easy for students to understand and semi-authentic. It is usually based on a vocabulary of about 1,500 high-frequency English words delivered at 90 words per minute. This step can be used to train students bottom-up strategy, that is, to listen to the details. It is a pre-listening activity . Students will be able to pick out key vocabulary such as name of the cities or countries and so forth. This, combined with their common knowledge which they obtain from the local media, will provide them background information and enable them to grasp the main idea of the news. Therefore, the Standard English News has been simplified at this stage.

\section{Helping learners to keep going.}

Teacher provides students the Standard English news of the same topic with the Special English. Inform the students that the news to be played will have the same topic as that they have just practiced listening to in Special English Program. This enables the students to use what they have previously learned to understand the same content when it is presented in a linguistically more difficult context. At this level, the news can be used as a basis for a discussion among the students. In teacher-assisted activities, discussions have a coherent focus and high level of participation [8]. During the discussion, it is important for teacher to offer assistance and instruction by providing one or two clues when necessary. After the discussion, the students are asked to transcript as much as they can. Since much related information and background information has been acquired from Special English, students will have a easier and better understanding of the relevant program in Standard English. This stage can train students to listen to the main idea and to use the top-down strategy.

4. Pointing out important differences between what has been provided and the ideal solution

At this stage, teacher can replay the news many times and ask students to identify the differences between the choices of vocabulary in different kinds of news items. The more difficult linguistic structures and more complicated words will be paid much attention. With the help of the Special English news, the predictions during listening to the Standard English news can be made and the grasping of most of the main idea can be achieved. This is an important way to teach students that it is unnecessary for them to understand every word in order to understand a message. Being able to rough out a message is also a good motivation for them .

5. Controlling frustrations during problem solving.

In scaffolding strategy, teacher controls the focus of the attention, demonstrates and segments the task. Teacher should manage to keep every student engage in the listening task by providing language-promoting assistance of varying types [8]. The teacher should make greater effort to choose the right pieces of news item for practice from Standard English program. The presentation speed, level of difficulty of vocabulary and structures, and appropriateness for the skills to be taught should 
be carefully considered, so that the students will not be discouraged. During the stretching of the student's ability to understand the Standard English, Teacher plays an important role, therefore, teacher should step in to control frustration and provide more scaffolding when necessary.

6. Demonstrating the ideal solution to the problem.

It is indicated that teacher should provide the transcripts of both kinds of news to students after class. Students can get a thorough understanding of the materials. Furthermore, students can compare it with the one they transcribed during the class and find out their problem area. This thoroughly helps to build a foundation for authentic listening task.

Reviewing the above six features, scaffolding is a very important teaching strategy especially when it is adopted with authentic listening materials. It is an effective approach to help students achieve higher level of listening comprehension ability.

\section{Conclusion}

Experience has shown that scaffolding strategy with authentic materials in listening teaching is very efficient to help learners to achieve advanced level of listening ability. Scaffolding strategy combined with authentic listening materials can be used for the training of advanced listening comprehension ability. Learners need an initially higher threshold of listening comprehension in order to benefit from listening strategy and instructions to deal with certain kinds of texts, such as news that are not visually reinforced. Good listening teachers provide scaffolding assistance for students who have trouble with listening skills and manage to stretch the listening abilities and strengthen the self confidence of all students. However, more evidence should be collected in later teaching.

\section{References}

[1] L. Vandergrift, Facilitating language listening comprehension: acquiring successful Strategies. ELT Journal, Vol. 53/3, pp.168-175, 1999.

[2] D. Krashen, Stephen, Principles and Practice in Second Language Acquisition, Oxford: Pergamon, 1982.

[3] P. Ur, Teaching Listening Comprehension. Cambridge: Cambridge University Press, 1984.

[4] Jack C Richards, John Platt \& Heidi Platt, Longman Dictionary of Language Teaching \& Applied Linguistics, Beijing: Foreign Laguages Teaching \& Research Press, pp. 403, 2000.

[5] L.S. Vygotsky, Thought and Language. Cambridge Mass: The MIT Press,1962.

[6] Y, G. Fan, Listening: Problems and solutions, English Teaching Forum, January,1993. pp.16-19,1993.

[7] D. Wood, , J. Bruner, \& G. Ross, The Role of Tutoring in Problem Solving, Journal of Child Psychology and Psychiatry, vol. 17, pp.89-100, 1976.

[8] R. C. Scarcella, \& R. L. Oxford, Language-Promoting Interaction, The Tapestry of Language Learning, USA: Newbury House, pp.29-47, 1992. 